\section{Stem Cell Mobilization with and without Plerixafor: A Comparative Analysis} Kröger $^{2}$, Hans Salwender ${ }^{3}$, Nadezda Basara ${ }^{4}$, Michael von Bergwelt-Baildon ${ }^{1}$, Christof Scheid $^{1}$, Michael Hallek ${ }^{1}$ and Kai Hübel ${ }^{1}$

${ }^{1}$ Department of Internal Medicine, University Hospital of Cologne, Cologne Germany

${ }^{2}$ Clinic and Policlinic for Stem cell Transplantation, University Hospital of Hamburg-Eppendorf, Hamburg, Germany

${ }^{3}$ Department of Internal Medicine, Asklepios Klinik Hamburg Altona, Hamburg, Germany

${ }^{4}$ Department of Internal Medicine, Malteser Hospital St. Franziskus, Flensburg, Germany diagnosed with MM and all patients with $\mathrm{HD}$ were able to collect the defined minimum of CD34+ cells. In total, $74.5 \%$ of poor mobilizing patients who received plerixafor gathered more than $2.0 \times 10^{\wedge} 6 / \mathrm{kg}$ BW CD34+ cells. Transplanted cells engrafted in both cohorts; however, in NHL and MM patients, engraftment of white blood cells and platelets were significant earlier in group $A$ than in group $B$.

In conclusion, only $4.3 \%$ of patients failed first mobilization attempt. For these limited number of patients plerixafor is a valuable additive.

Keywords: Plerixafor; Poor mobilization

\section{Abbreviations}

NHL: Non-Hodgkin Lymphoma

MM: Multiple Myeloma

HD: Hodgkin Lymphoma

Group A: Patients in first mobilization

Group B: Proven poor mobilizers

BW: Body weight

PB: Peripheral blood

\section{Introduction}

High-dose chemotherapy followed by autologous stem cell transplantation is an approved therapeutic intervention in numerous malignant as well as non-malignant diseases [1]. Since more than one decade, the possibility of collecting Peripheral Blood Stem Cells (PBSC) as primary source for stem cell transplantation has largely replaced the use of bone marrow cells [2,3]. Hematopoietic Stem Cells (HSC) and progenitor cells, identifiable by the expression of CD34 [4], reside in a special environment of the bone marrow, the stem cell niche. Because of their physiologically low presence in peripheral blood, HSC have to be mobilized from the bone marrow into circulation prior to collection by apheresis. For mobilization, most investigators use hematopoietic growth factors like Granulocyte Stimulating Factor (G-CSF) without or with chemotherapy ("chemomobilization").

The success of autologous stem cell transplantation relies on multiple factors, with the dose of reinfused HSC being a key factor [5]. Most investigators define the minimum dose of HSC necessary to allow a prompt and durable engraftment as $2 \times 10^{\wedge} 6 \mathrm{CD} 34+$ cells $/ \mathrm{kg}$ Body Weight $(\mathrm{BW})$ or $4 \times 10^{\wedge} 6 \mathrm{CD} 34+$ cells $/ \mathrm{kg}$ BW for patients with multiple myeloma scheduled for tandem transplantation [6-8]. Unfortunately, some patients undergoing mobilization attempts are unable to reach the required minimum, being considered as "poor mobilizers". In literature, the rate of poor mobilizers differs between $5 \%$ and $46 \%$ [9-12]. If patients fail an initial mobilization, they often undergo additional mobilization attempts, which increases the risk associated with treatment [13]. Since December 2008 the bicyclam plerixafor is available to increase mobilization success. Plerixafor was found to interrupt the interaction between chemokine Stromal-Cell Derived Factor-1 alpha (SDF-1a) [14], which is constitutively expressed

Received: December 20, 2017; Accepted: February 09, 2018; Published: February 23,2018 
on bone marrow stromal cells, and its cognate receptor CXCR4 on CD34+ HSC [15], resulting in a rapid increase of PBSC [16]. In a phase I study, a single dose of $240 \mu \mathrm{g} / \mathrm{kg}$ BW SC was as affective as a five-day mobilization regimen with G-CSF [17]. Before approval plerixafor was applied in two major registration trials in patients with Non-Hodgkin Lymphoma (NHL) [18] and Multiple Myeloma (MM) [19] undergoing first mobilization as well as in Compassionate-Use-Programs (CUP) around the world for patients who failed as least one conventional mobilization regimen.

In this work we analyzed patients receiving their first mobilization to evaluate the number requiring a second mobilization attempt. In a matched pair process, these patients were compared to a group of second mobilizers receiving plerixafor. This analysis will allow us to describe the actual need for plerixafor and the re-mobilization success in comparable patients.

\section{Materials and Methods}

In a first step we evaluated retrospectively the mobilization success of a group of 47 patients treated at the university hospital of cologne between 2007 and 2010 (group A). Twenty-eight patients were diagnosed with NHL, 17 with MM and 2 with Hodgkin Lymphoma (HD). Prior to mobilization patients had received a median of 1 (range $0-5$ ) line of treatment. The ratio between chemomobilization and cytokine only was $24 / 4$ for NHL, $14 / 3$ for MM and 2/0 for HD, respectively.

Patients included in group A were matched by age, sex and diagnosis to a group of proven poor mobilizers enrolled in the German plerixafor Compassionate Use Program (CUP) between May 2008 and August 2009 [20] (group B). In the CUP 60 patients were enrolled; however, 13 patients with other diagnoses than NHL, MM and $\mathrm{HD}$ and also minors were excluded from the analysis. Patients included in group B had received a median of 3 (range 1-5) prior lines of treatment. All patients received plerixafor and G-CSF with or without chemotherapy for a second mobilization attempt.

Mobilization without chemotherapy started with a four-day treatment of non-pegylated G-CSF. In general, a subcutaneous dosage of $10 \mu \mathrm{g} / \mathrm{kg}$ daily was administered in the morning. Patients in group B received plerixafor $\left(240 \mu \mathrm{g} / \mathrm{kg}\right.$; Mozobil ${ }^{\mathrm{TM}}$, Genzyme Inc., Naarden, $\mathrm{NL}$ ) in the evening of the fourth day subcutaneously 11 hours prior to apheresis. G-CSF was given on day five 1 hour before apheresis. If multiple days of collection were required, the schedule of plerixafor and G-CSF was repeated until a maximum of seven days of plerixafor injections. Patients in group B were also allowed to receive a combination of chemotherapy with G-CSF and plerixafor for mobilization. In this case, G-CSF was started at the neutrophil nadir after chemotherapy.

Patients were considered as poor mobilizers if at least one mobilization regimen was unable to increase the peripheral blood count of CD34+ cells above 10 cells/ $\mu 1$ in multiple measurements or if patients were unable to collect the required minimum of at least 2,0 $\times$ $10^{\wedge} 6 \mathrm{CD} 34+$ cells $/ \mathrm{kg}$ BW within five apheresis sessions. Measurement of CD34+ cells was started on the day of leukocyte recovery or at last beginning on day five after application of G-CSF. Apheresis procedure was started if CD34+ cell counts exceeded 10 cells $/ \mu 1$ in peripheral blood. Flow cytometry was used for detection of CD34+ cells. Volume, processing, and storage of apheresis product were done according to the standardized procedures (approximately 3 times blood volume). Aphereses were performed using continuous-flow blood cell separators on consecutive days for a maximum of 7 collections. Pooling of collected CD34+ cells was allowed. The trial was conducted according to the standards of ethical principles. Patients had to sign an informed consent prior to administration of plerixafor.

\section{Results}

A total of 47 patients were enrolled in group A. Characteristics of the patients are shown in table 1 . Of 28 patients diagnosed with NHL, $24(85.7 \%)$ were mobilized with a combination of chemotherapy and G-CSF and yielded a median of $5.08 \times 10^{\wedge} 6 \mathrm{CD} 34+$ cells $/ \mathrm{kg} \mathrm{BW}$ (range 1.1-41.4). Twenty-two (91.7\%) reached the defined minimum and proceeded to high-dose chemotherapy followed by autologous stem cell transplantation. A median of one (range 1-3) apheresis procedure was needed. Four NHL patients $(14.3 \%)$ received G-CSF only for mobilization purpose and had a median of $6.67 \times 10^{\wedge} 6 \mathrm{CD} 34+$ cells $/ \mathrm{kg}$ BW (range 3.6-11.2) collected, allowing all patients to undergo transplantation. All four patients yielded enough CD34+ cells in one single apheresis.

Fourteen of 17 patients $(82.4 \%$ ) diagnosed with MM received chemomobilization and gathered a median of $6.15 \times 10^{\wedge} 6 \mathrm{CD} 34+$ cells $/ \mathrm{kg}$ BW (range 2.6-13.0) in a median of 2 (range 1-4) aphereses, whereas three patients $(17.6 \%)$ mobilized with G-CSF only yielded a median of $5.71 \times 10^{\wedge} 6 \mathrm{CD} 34+$ cells $/ \mathrm{kg} \mathrm{BW}$ (range 4.9-8.6) in a median of 2 apheresis sessions (range 1-3). All patients with MM were able to collect a sufficient amount of cells to undergo transplantation.

Two patients diagnosed with HD received a combination of chemotherapy and G-CSF for mobilization and yielded a median of 6.44 $\times 10^{\wedge} 6 \mathrm{CD} 34+$ cells $/ \mathrm{kg} \mathrm{BW}$ (range 5.6-7.3). Both patients proceeded to transplantation after undergoing one single apheresis.

In total $95.7 \%(45 / 47)$ of patients in group A were able to collect a median of $5.71 \times 10^{\wedge} 6 \mathrm{CD} 34+$ cells $/ \mathrm{kg} \mathrm{BW}$ (range 1.1-41.4) to proceed to high dose chemotherapy followed by autologous stem cell transplantation. A median of 2 apheresis procedures (range 1-4) were necessary for yielding the required minimum of CD34+ cells.

In the matching group B, 85.7\% (24/28) of the NHL-patients, who received chemomobilization combined with plerixafor yielded a median of $2.29 \times 10^{\wedge} 6 \mathrm{CD} 34+$ cells $/ \mathrm{kg} \mathrm{BW}$ (range 0-8.77) in a median of 2 aphereses (range 0-3), allowing 13 patients (54.2\%) to undergo high dose chemotherapy. Four patients diagnosed with NHL treated with G-CSF and plerixafor collected a median of $2.1 \times 10^{\wedge} 6 \mathrm{CD} 34+$ cells/ kg BW (range 1.6-3.7). Three of them (75\%) underwent transplantation after undergoing a median of 2.5 apheresis procedures (range 1 -3). Patients diagnosed with NHL in group B received a median of 2 (range 1-4) doses of plerixafor.

A median of $4.94 \times 10^{\wedge} 6 \mathrm{CD} 34+$ cells $/ \mathrm{kg} \mathrm{BW}$ (range 0-10.98) were collected in $82.4 \%$ (14/17) of the MM patients mobilized by a combination of chemotherapy, G-CSF and plerixafor, allowing 12 patients $(85.7 \%)$ to undergo transplantation. Those patients had to undergo a median of 2 apheresis days (range $0-5$ ) and received a median of 2 (range 1-3) doses of plerixafor. Three MM patients who underwent "steady state" mobilization with plerixafor and G-CSF gathered a median of $5.43 \times 10^{\wedge} 6 \mathrm{CD} 34+$ cells $/ \mathrm{kg}$ BW (range 4.4-8.7). All three patients received plerixafor for two consecutive days and proceeded to high dose chemotherapy. 
Citation: Fresen MM, Lange F, Kröger N, Salwender H, Basara N, et al. (2018) Stem Cell Mobilization with and without Plerixafor: A Comparative Analysis. J Hematol Blood Transfus Disord 5: 018.

\begin{tabular}{|c|c|c|c|c|c|c|c|c|}
\hline \multirow{3}{*}{$\mathrm{N}(\%)$} & \multicolumn{2}{|c|}{ NHL } & \multicolumn{2}{|c|}{ MM } & \multicolumn{2}{|c|}{ HD } & \multicolumn{2}{|c|}{ Total } \\
\hline & Group A & Group B & Group A & Group B & Group A & Group B & Group A & Group B \\
\hline & $28(59.6)$ & $28(59.6)$ & $17(36.2)$ & $17(36.2)$ & $2(4.3)$ & $2(4.3)$ & $47(100.0)$ & $47(100.0)$ \\
\hline \multicolumn{9}{|l|}{ Age (years) } \\
\hline Mean (s) & $54.5(12.2)$ & $57.46(9.64)$ & $60.94(8.31)$ & $60.88(7.70)$ & $28(7.07)$ & $20.0(1.41)$ & $55.7(12.52)$ & $57.11(11.85)$ \\
\hline Median & 57.5 & 57 & 63 & 60 & 28 & 20 & 59 & 59 \\
\hline Min, Max & 21,71 & 38,75 & 44,74 & 46,70 & 23,33 & 19,21 & 21,74 & 19,75 \\
\hline \multicolumn{9}{|l|}{$\operatorname{Sex}(\%)$} \\
\hline Female & $14(50.0)$ & $14(50.0)$ & $7(41.2)$ & $7(41.2)$ & $2(100.0)$ & $2(100.0)$ & $23(48,9)$ & $23(48,9)$ \\
\hline Male & $14(50.0)$ & $14(50.0)$ & $10(58.8)$ & $10(58.8)$ & $0(0.0)$ & $0(0.0)$ & $24(51,1)$ & $24(51,1)$ \\
\hline \multicolumn{9}{|l|}{ Prior lines of treatment } \\
\hline Median (range) & $1(0,5)$ & $3(1,4)$ & $1(1,4)$ & $3(1,5)$ & $1.5(1,2)$ & $3.5(3,4)$ & $1(0,5)$ & $3(1,5)$ \\
\hline Radiation pretreatment (\%) & $4(8.5)$ & $5(10.6)$ & $3(6.4)$ & $5(10.6)$ & $1(2.1)$ & $0(0.0)$ & $8(17.0)$ & $10(21.3)$ \\
\hline
\end{tabular}

Table 1: Patients characteristics.

Two patients diagnosed with HD were treated with chemomobilization and plerixafor and collected a median of $2.41 \times 10^{\wedge} 6 \mathrm{CD} 34+$ cells/kg BW (range 2.01-2.8). Although both patients reached the defined minimum in two aphereses after receiving 2 doses of plerixafor, one patient declined to receive high-dose therapy and transplantation.

In total, $74.47 \%(35 / 47)$ of proven poor mobilizers in group B reached the defined minimum of $\mathrm{CD} 34+$ cells after a mobilization regimen containing plerixafor. Thirty-two of them (91.4\%) underwent transplantation. Two patients with a poor performance status declined high-dose chemotherapy and transplantation and received best supportive care; one patient died from high dose chemotherapy.

In the CUP, engraftment of White Blood Cells (WBC) was defined as a WBC count of $>1.0 \times 10^{\wedge} 9 / 1$ following autologous stem cell transplantation. Measurement of more than $20 \times 10^{\wedge} 9 / 1$ platelets without transfusions was defined as platelet engraftment. In group A of NHL patients WBC engraftment could be observed after a median of 9 days (range 7-15 days) and in group B after a median of 12 days (range 7-14) $(\mathrm{P}=0.042)$. Platelets recovered after a median of 10 days (range 7-15) in group A and after a median of 13 days (range 8-36) in group $\mathrm{B}(\mathrm{P}=0.023)$, respectively. $\mathrm{WBC}$ of patients diagnosed with MM recovered after a median of 11 days (range 6-13) in group $A$ and after a median 13.5 days (range $10-27)$ in group $\mathrm{B}(\mathrm{P}=0.02)$. Platelet recovery in group A occurred after a median of 10 days (range 6-11) and in group B after a median of 18 days $(13-24)(P<0.0001)$.

The most common side effects in patients receiving plerixafor were gastro-intestinal disorders and exhaustion observed in three patients, followed by dyspnea, sweating and injection side pain observed in one patient. All adverse events were mild and manageable.

Overall, the rate of mobilization failure in patients of group A (first mobilization without plerixafor) was $4.25 \%$ (2/47). Poor mobilizers receiving plerixafor (group B) had a mobilization success of $74.47 \%$ (35/47). Results are shown in table 2.

\section{Discussion}

Several major findings emerge from this analysis: 1) In Hodgkin lymphoma and multiple myeloma patients, the rate of failed mobilization is rare; 2) Patients with non-Hodgkin lymphoma have a higher rate of failed mobilization; 3) In those patients mobilizing poorly, plerixafor is effective in three-fourth of patients for rescue mobilization; 4) The second mobilization attempt is less effective in non-Hodgkin lymphoma patients 5) Recovery of WBC and platelets takes significantly longer in patients being considered as poor-mobilizers.

High-dose chemotherapy followed by autologous stem cell transplantation represents the standard of care for patients suffering from relapsed lymphoma and newly diagnosed multiple myeloma. Successful mobilization of hematopoietic stem cells is the essential precondition for this procedure. Therefore, most patients who mobilize poorly cannot benefit from it and are likely to have an inferior prognosis.

In 1998, Desikan et al., compared the mobilization success of 44 patients diagnosed with multiple myeloma in a randomized fashion. One group received a mobilization regimen with cytokines and cyclophosphamide, the other group received G-CSF alone. Failure rates were $18 \%$ in the chemomobilization group and $23 \%$ in the cytokines group, respectively. Although patients receiving cyclophosphamide yielded greater $\mathrm{CD} 34$ cell quantities, median recovery times following transplantation were similar in both groups [21].

In a large, retrospective evaluation, Pusic et al., compared the records of 1040 patients (502 NHL, $137 \mathrm{HD}, 401 \mathrm{MM}$ ) of which 976 received G-CSF and 64 a combination of chemotherapy and G-CSF. Although the median $\mathrm{CD} 34+$ cell yield was higher in the group of chemomobilized patients than in the cytokine-mobilized group, the failure rates were comparable: $18.6 \%$ versus $18.8 \%$. Two-hundredsixty-nine patients received a remobilization attempt with G-CSF or GM-CSF alone or combined with chemotherapy and/or plerixafor. Failure rates in remobilization showed a significant difference between the remobilization regimens: G-CSF and/or GM-CSF $81.6 \%$, chemomobilization $73.5 \%$ and G-CSF with plerixafor $27.8 \%(\mathrm{P}<$ $0.001)$, respectively [7]. 
Citation: Fresen MM, Lange F, Kröger N, Salwender H, Basara N, et al. (2018) Stem Cell Mobilization with and without Plerixafor: A Comparative Analysis. J Hematol Blood Transfus Disord 5: 018.

- Page 4 of 6 •

\begin{tabular}{|c|c|c|c|c|c|c|}
\hline \multirow[t]{2}{*}{ NHL } & \multicolumn{2}{|c|}{ Cytokines } & \multicolumn{2}{|c|}{ Chemomobilization } & \multicolumn{2}{|c|}{ Total } \\
\hline & Group A & Group B & Group A & Group B & Group A & Group B \\
\hline $\mathrm{N}(\%)$ & $4(8.51)$ & $4(8.51)$ & $24(51.06)$ & $24(51.06)$ & $28(59.57)$ & $28(59.57)$ \\
\hline \multicolumn{7}{|l|}{ No of apheresis sessions } \\
\hline Median (range) & $1(1,1)$ & $2,5(1,3)$ & $1(1,3)$ & $2(0,3)$ & $1(1,3)$ & $2(0,3)$ \\
\hline \multicolumn{7}{|c|}{ CD34+ prior to apheresis in $\mathrm{PB}(/ \mu \mathrm{I})$} \\
\hline Median & 85.1 & 22.75 & 54.93 & 13.95 & 58 & 14.5 \\
\hline Min, Max & $40.9,224$ & $22.5,23$ & $9.8,442$ & 3,47 & $9.8,442$ & 3,47 \\
\hline \multicolumn{7}{|c|}{ CD34+ cell yield $\left(\times 10^{\wedge} 6 / \mathrm{kg} B W\right)$} \\
\hline Median & 6.67 & 2.09 & 5.08 & 2.29 & 5.08 & 2.21 \\
\hline Min, Max & $3.6,11.2$ & $1.6,3.7$ & $1.1,41.4$ & $0,8.77$ & $1.1,41.4$ & $0,8.77$ \\
\hline Transplanted (\%) & $4(8.51)$ & $3(6.38)$ & $22(46.81)$ & $13(21.67)$ & $26(55.32)$ & $16(26.67)$ \\
\hline \multicolumn{7}{|c|}{ Engraftmet of leucocytes (days) $>1,0 \times 10^{\wedge} 9 / 1$} \\
\hline Median (range) & $8.5(8,15)$ & $12(12,12)$ & $9(7,13)$ & $11(7,14)$ & $9(7,15)$ & $12(7,14)$ \\
\hline \multicolumn{7}{|c|}{ Engraftment of thrombcytes (days) $>20 \times 10^{\wedge} 9 / 1$} \\
\hline \multirow{3}{*}{$\begin{array}{c}\text { Median (range) } \\
\mathbf{M M}\end{array}$} & $9.5(9,15)$ & $13(13,14)$ & $10(7,14)$ & $13(8,36)$ & $10(7,15)$ & $13(8,36)$ \\
\hline & \multicolumn{2}{|c|}{ Cytokines } & \multicolumn{2}{|c|}{ Chemomobilization } & \multicolumn{2}{|c|}{ Total } \\
\hline & Group A & Group B & Group A & Group B & Group A & Group B \\
\hline $\mathrm{N}(\%)$ & $3(6.38)$ & $3(6.38)$ & $14(29.79)$ & $14(29.79)$ & $17(36.17)$ & $17(36.17)$ \\
\hline \multicolumn{7}{|l|}{ No of apheresis sessions } \\
\hline Median (range) & $2(1,3)$ & $2(2,2)$ & $2(1,4)$ & $2(0,5)$ & $2(1,4)$ & $2(0,5)$ \\
\hline \multicolumn{7}{|c|}{$\mathrm{CD} 34+$ prior to apheresis in $\mathrm{PB}(/ \mu \mathrm{I})$} \\
\hline Median & 89 & 50.2 & 28.35 & 16 & 33.39 & 26.5 \\
\hline Min, Max & $26.6,179.8$ & $50.2,50.2$ & $11.8,274.5$ & $4,68.85$ & $11.84,274.48$ & $4,68.85$ \\
\hline \multicolumn{7}{|c|}{ CD34 + cell yield $\left(\times 10^{\wedge} 6 / \mathrm{kg} \mathrm{BW}\right)$} \\
\hline Median & 5.71 & 5.43 & 6.15 & 4.94 & 5.96 & 5.38 \\
\hline Min, Max & $4.9,8.6$ & $4.4,8.7$ & $2.6,13.0$ & $0,10.98$ & $2.6,13.0$ & $0,10.98$ \\
\hline Transplanted (\%) & $3(6.38)$ & $3(6.38)$ & $14(29.79)$ & $12(25.53)$ & $17(36.17)$ & $15(31.91)$ \\
\hline \multicolumn{7}{|c|}{ Engraftmet of leucocytes (days) $>1,0 \times 10^{\wedge} 9 / 1$} \\
\hline Median (range) & $11(10,12)$ & $14(12,17)$ & $11(6,13)$ & $13,5(10,27)$ & $11(6,13)$ & $13(10,27)$ \\
\hline \multicolumn{7}{|c|}{ Engraftment of thrombcytes (days) $>20 \times 10^{\wedge} 9 / 1$} \\
\hline Median (range) & $10(10,11)$ & $18(15,22)$ & $10(6,11)$ & $18(13,24)$ & $10(6,11)$ & $18(13,24)$ \\
\hline \multirow[t]{2}{*}{ Hodgkin Lymphoma } & \multicolumn{2}{|c|}{ Cytokines } & \multicolumn{2}{|c|}{ Chemomobilization } & \multicolumn{2}{|c|}{ Total } \\
\hline & Group A & Group B & Group A & Group B & Group A & Group B \\
\hline $\mathrm{N}(\%)$ & $0(0.0)$ & $0(0.0)$ & $2(4.26)$ & $2(4.26)$ & $2(4.26)$ & $2(4.26)$ \\
\hline No of apheresis sessions & 0 & 0 & & & & \\
\hline Median (range) & 0,0 & 0,0 & $1(1,1)$ & $2(2,2)$ & $1(1,1)$ & $2(2,2)$ \\
\hline CD34+ prior to apheresis ir & & & & & & \\
\hline Median & 0 & 0 & 115 & 8.6 & 115 & 8.6 \\
\hline Min, Max & 0 & 0 & 106,124 & $8.6,8.6$ & 106,124 & $8.6,8.6$ \\
\hline CD34 + cell yield $\left(\times 10^{\wedge} 6 / \mathrm{k}\right.$ & & & & & & \\
\hline Median & 0 & 0 & 6.44 & 2.41 & 6.44 & 2.41 \\
\hline Min, Max & 0 & 0 & $5.6,7.3$ & $2.01,2.8$ & $5.6,7.3$ & $2.01,2.8$ \\
\hline Transplanted (\%) & $0(0.0)$ & $0(0.0)$ & $2(4.26)$ & $1(2.13)$ & $2(4.26)$ & $1(2.13)$ \\
\hline Engraftmet of leucocytes (d & $1,0 \times 10^{\wedge} 9 / 1$ & & & & & \\
\hline Median (range) & $0(0.0)$ & $0(0.0)$ & $9.5(9,10)$ & $0(0,0)$ & $9.5(9,10)$ & $0(0,0)$ \\
\hline Engraftment of thrombcyte & s) $>20 \times 10$ & & & & & \\
\hline Median (range) & $0(0.0)$ & $0(0.0)$ & $9.5(9,10)$ & $0(0,0)$ & $9.5(9,10)$ & $0(0,0)$ \\
\hline
\end{tabular}

Table 2: Results of rate of mobilization. 
Ozkurt et al., [22] evaluated the effectiveness of various mobilization regimens to determine risk factors for poor mobilization and reported an overall failure rate of $11.8 \%$ in a total of 118 patients including 21 diagnosed with NHL, 56 with MM and 35 with HD. Patients diagnosed with NHL and HD were analyzed together. Failure rates were higher in patients diagnosed with lymphoma (12/56) than in patients diagnosed with $\mathrm{MM}(1 / 56)(\mathrm{P}<0.001)$ and in patients receiving "steady-state" mobilization with G-CSF alone $(5 / 15)(\mathrm{P}=$ $0.01)$.

In 2008 Calandra et al., [23] evaluated plerixafor in 115 patients within the AMD3100 compassionate use program. The overall mobilization success was $>66 \%$; similar to our analysis, mobilization success of patients diagnosed with MM (75\%) was higher than in NHL $(65,5 \%)$. Median time to WBC engraftment post-transplant was 11 days and median time to PLT engraftment was 18 days. Although median time to WBC engraftment were similar in NHL and MM patients, PLT engraftment was observed earlier in patients diagnosed with NHL (median 18 days) than in patients diagnosed NHL (median 21 days).

Compassionate use data from the United Kingdom and Spain published by Duarte et al., in 2011 showed an overall mobilization success of $75 \%$ ( $42 / 56$ patients). Thirty-five patients underwent autologous stem cell transplantation. In contrast to other publications, there were no differences in WBC or PLT engraftment between NHL and MM patients [24].

The results of our analysis emphasize that modern mobilization regimens using G-CSF alone or in combination with chemotherapy are effective in the vast majority of patients. Although some algorithms predicting poor mobilization in patients with delayed hematopoietic recovery after mobilization with chemotherapy and G-CSF or insufficient increase of CD34+ cells in peripheral blood encourage the preemptive use of plerixafor $[25,26]$, the low rate of mobilization failure in our cohort as well as in other publications [6,27] do not support the use of plerixafor in first-line mobilization. However, plerixafor is a very valuable option for poor mobilizers, allowing the majority of these patients to proceed to autologous stem cell transplantation and thus benefit from high-dose chemotherapy. This is further supported by the lack of relevant toxicity of plerixafor and safe engraftment following transplantation.

\section{Conflict of Interest}

The authors declare that they have no conflicts of interest relevant to the manuscript.

\section{References}

1. Demirer T, Bensinger WI, Buckner CD (1999) Peripheral blood stem cell mobilization for high-dose chemotherapy. J Hematother 8: 103-113.

2. Beyer J, Schwella N, Zingsem J, Strohscheer I, Schwaner I, et al. (1995) Hematopoietic rescue after high-dose chemotherapy using autologous peripheral-blood progenitor cells or bone marrow: A randomized comparison. J Clin Oncol 13: 1328-1335.

3. Hartmann O, Le Corroller AG, Blaise D, Michon J, Philip I, et al. (1997) Peripheral blood stem cell and bone marrow transplantation for solid tumors and lymphomas: Hematologic recovery and costs. A randomized, controlled trial. Ann Intern med 126: 600-607.
4. Fruehauf S, Haas R, Conradt C, Murea S, Witt B, et al. (1995) Peripheral Blood Progenitor Cell (PBPC) counts during steady-state hematopoiesis allow to estimate the yield of mobilized PBPC after filgrastim (R-metHuG-CSF)-supported cytotoxic chemotherapy. Blood 85: 26192626.

5. Jillella AP, Ustun C (2004) What is the optimum number of CD34+ peripheral blood stem cells for an autologous transplant? Stem Cells Dev 13: 598-606.

6. Bensinger W, Appelbaum F, Rowley S, Storb R, Sanders J, et al. (1995) Factors that influence collection and engraftment of autologous peripheral-blood stem cells. J Clin Oncol 13: 2547-2555.

7. Pusic I, Jiang SY, Landua S, Uy GL, Rettig MP, et al. (2008) Impact of mobilization and remobilization strategies on achieving sufficient stem cell yields for autologous transplantation. Biol Blood Marrow Transplant 14: $1045-1056$

8. Villalon L, Odriozola J, Larana JG, Zamora C, Perez de Oteyza J, et al. (2000) Autologous peripheral blood progenitor cell transplantation with $<2 \times 10(6) \mathrm{CD} 34(+) / \mathrm{kg}$ : An analysis of variables concerning mobilisation and engraftment. Hematol J 1: 374-381.

9. Kessinger A, Sharp JG (2003) The whys and hows of hematopoietic progenitor and stem cell mobilization. Bone marrow transplant 31: 319-329.

10. Koenigsmann M, Jentsch-Ullrich K, Mohren M, Becker E, Heim M, et al. (2004) The role of diagnosis in patients failing peripheral blood progenitor cell mobilization. Transfusion 44: 777-784.

11. Mendrone A, Arrais CA, Saboya R, Chamone Dde A, Dulley FL (2008) Factors affecting hematopoietic progenitor cell mobilization: An analysis of 307 patients. Transfus Apher Sci 39: 187-192.

12. Moog R (2008) Management strategies for poor peripheral blood stem cell mobilization. Transfus Apher Sci 38: 229-236.

13. Gazitt Y, Freytes CO, Callander N, Tsai TW, Alsina M, et al. (1999) Successful PBSC mobilization with high-dose G-CSF for patients failing a first round of mobilization. J Hematother 8: 173-183.

14. Nagasawa T (2000) A chemokine, SDF-1/PBSF, and its receptor, CXC chemokine receptor 4 , as mediators of hematopoiesis. Int J Hematol 72: 408-411.

15. Mohle R, Bautz F, Rafii S, Moore MA, Brugger W, et al. (1998) The chemokine receptor CXCR-4 is expressed on CD34+ hematopoietic progenitors and leukemic cells and mediates transendothelial migration induced by stromal cell-derived factor-1. Blood 91: 4523-4530.

16. Akhtar S, Weshi AE, Rahal M, Khafaga Y, Tbakhi A, et al. (2008) Factors affecting autologous peripheral blood stem cell collection in patients with relapsed or refractory diffuse large cell lymphoma and Hodgkin lymphoma: a single institution result of 168 patients. Leuk Lymphoma 49: 769778 .

17. Liles WC, Rodger E, Broxmeyer HE, Dehner C, Badel K, et al. (2005) Augmented mobilization and collection of CD34+ hematopoietic cells from normal human volunteers stimulated with granulocyte-colony-stimulating factor by single-dose administration of AMD3100, a CXCR4 antagonist. Transfusion 45: 295-300.

18. DiPersio JF, Micallef IN, Stiff PJ, Bolwell BJ, Maziarz RT, et al. (2009) Phase III prospective randomized double-blind placebo-controlled trial of plerixafor plus granulocyte colony-stimulating factor compared with placebo plus granulocyte colony-stimulating factor for autologous stem-cell mobilization and transplantation for patients with non-Hodgkin's lymphoma. J Clin Oncol 27: 4767-4773.

19. Micallef IN, Stiff PJ, DiPersio JF, Maziarz RT, McCarty JM, et al. (2009) Successful stem cell remobilization using plerixafor (mozobil) plus granulocyte colony-stimulating factor in patients with non-hodgkin lymphoma: Results from the plerixafor NHL phase 3 study rescue protocol. Biol Blood Marrow Transplant 15: 1578-1586. 
20. Hubel K, Fresen MM, Salwender H, Basara N, Beier R, et al. (2011) Plerixafor with and without chemotherapy in poor mobilizers: Results from the German compassionate use program. Bone marrow transplant 46: 1045-1052.

21. Desikan KR, Barlogie B, Jagannath S, Vesole DH, Siegel D, et al. (1998) Comparable engraftment kinetics following peripheral-blood stem-cell infusion mobilized with granulocyte colony-stimulating factor with or without cyclophosphamide in multiple myeloma. J Clin Oncol 16: 1547-1553.

22. Ozkurt ZN, Yegin ZA, Suyani E, Aki SZ, Acar K, et al. (2010) Factors affecting stem cell mobilization for autologous hematopoietic stem cell transplantation. J Clin Apher 25: 280-286.

23. Calandra G, McCarty J, McGuirk J, Tricot G, Crocker SA, et al. (2008) AMD3100 plus G-CSF can successfully mobilize CD34+ cells from non-Hodgkin's lymphoma, Hodgkin's disease and multiple myeloma patients previously failing mobilization with chemotherapy and/or cytokine treatment: Compassionate use data. Bone Marrow Transplant 41: 331-338.
24. Duarte RF, Shaw BE, Marin P, Kottaridis P, Ortiz M, et al. (2011) Plerixafor plus granulocyte CSF can mobilize hematopoietic stem cells from multiple myeloma and lymphoma patients failing previous mobilization attempts: EU compassionate use data. Bone Marrow Transplant 46: 52-58.

25. Farina L, Spina F, Guidetti A, Longoni P, Ravagnani F, et al. (2014) Peripheral blood CD34+ cell monitoring after cyclophosphamide and granulocyte-colony-stimulating factor: An algorithm for the pre-emptive use of plerixafor. Leuk Lymphoma 55: 331-336.

26. Abhyankar S, DeJarnette S, Aljitawi O, Ganguly S, Merkel D, et al. (2012) A risk-based approach to optimize autologous Hematopoietic Stem Cell (HSC) collection with the use of plerixafor. Bone Marrow Transplant 47: 483-487.

27. Fowler CJ, Dunn A, Hayes-Lattin B, Hansen K, Hansen L, et al. (2009) Rescue from failed growth factor and/or chemotherapy HSC mobilization with G-CSF and plerixafor (AMD3100): An institutional experience. Bone Marrow Transplant 43: 909-917. 